\title{
LAS TEORÍAS MÉTRICAS DE PIETRO BEMBO EN LAS PROSE DELLA VOLGAR LINGUA (PROSE NELLE QUALI SI RAGIONA DELLA VOLGAR LINGUA)
}

\author{
PIETRO BEMBO'S METRICAL THEORIES IN \\ PROSE DELLA VOLGAR LINGUA (PROSE NELLE \\ QUALI SI RAGIONA DELLA VOLGAR LINGUA)
}

\author{
IsABel PARAÍSO \\ Universidad de Valladolid
}

\begin{abstract}
Resumen: Se presentan aquí las teorías métricas de Pietro Bembo, expuestas en las muy importantes Prose della volgar lingua (1525), primera Gramática del volgare italiano. La teoría métrica es breve y generalista. Clasifica los poemas en tres tipos; atiende a valores estilísticos de las rimas, y suministra cinco criterios para valorar a un escritor.
\end{abstract}

Palabras clave: Bembo, Métrica, Petrarca, lengua italiana vernácula (volgare).

Abstract: This paper studies Pietro Bembo's metrical theory as found in his Prose della volgar lingua (1525), the first grammar of vernacular Italian. Bembo's theory of metrics is concise and general in character. Italian poems are classified into three groups. Particular attention is paid to the stylistics of rhyme. Bembo also offers five criteria for judging a writer's works.

Key words: Bembo, Versification, Petrarch, Italian vernacular. 



\section{Introducción}

1 ietro Bembo nació en Venecia en 1470, de noble familia, y falleció en Roma en 1547. Su padre, Bernardo Bembo, 1 embajador de Venecia, bibliófilo y amante del arte, llevó consigo al niño Pietro a Florencia entre 1478 y 1479, donde aprendió a apreciar la lengua toscana, y a preferirla a la propia, el veneciano. El amor de su padre por la literatura le llevó a erigir un monumento a Dante en la ciudad de Ravenna, donde había muerto el genio, y en otros lugares de Italia. Pietro estudia con excelentes preceptores; entre ellos el griego Costantino Lascaris, que le enseña su lengua en Messina (1492-1494). Se licencia en la Universidad de Padua.

Después de una estancia en la corte de los D'Este, en Ferrara (donde encuentra a Lucrezia Borgia, esposa de Alfonso D’Este, y siente por ella una platónica amistad que durará años), se traslada en 1506, huyendo de la peste, a Urbino, donde se convierte en figura destacada de un grupo de intelectuales reunidos en torno a la corte. En 1508 comienza su carrera eclesiástica. En 1513 acompaña a su amigo Giuliano de' Medici (uno de los futuros interlocutores de las Prose) a Roma, donde poco después el papa León X (Giovanni de' Medici) le nombra secretario personal. Permanece en Roma ocho años, estimado por todos. A la muerte de León X, en 1521, se retira a Padua, donde vivía su amante Faustina Morosina della Torre (con la cual tuvo tres hijos; Morosina fallece en 1535). Allí vive rodeado de un selecto grupo de amigos, y dedicado a tareas literarias. Durante su estancia en Padua publica en Venecia las Prose della volgar lingua. Reúne una extensa biblioteca y un pequeño museo de antigüedades.

En 1529 es nombrado historiador de la República de Venecia, y bibliotecario de la Biblioteca Marciana. También ese año 
asiste en Bolonia a la coronación de Carlos V como emperador. En 1539 el papa Pablo III lo llama a Roma y le nombra cardenal. A partir de ahora renuncia al estudio de los clásicos y se dedica a profundizar en los Padres de la Iglesia y en las Sagradas Escrituras. Le nombran obispo de Gubbio y después de Bérgamo. Muere en Roma en 1547, a los 76 años, estimado y admirado por todos. Está enterrado cerca del papa León X, en la iglesia de Santa Maria sopra Minerva, detrás del altar mayor.

Humanista, poeta y ensayista, poseyó un estilo magistral, tanto en latín como en italiano. Sus obras principales son: como lingüista, Prose della volgar lingua (1525), donde establece el canon de la lengua italiana. Como historiador, Rerum Veneticarum Libri XII (1551), que contiene la historia de Venecia entre 1487 y 1513. Como ensayista y filósofo, Gli Asolani (1505) ${ }^{1}$, dedicado a Lucrezia Borgia, es un diálogo sobre el amor platónico, que sigue el modelo de las Tusculanae Disputationes de Cicerón. Como poeta, escribió en italiano Rime (1530), y en latín Carmina (1533). También redactó varios volúmenes de cartas en latín, género en el que desplegó sus grandes dotes. Y además, editó en la imprenta de Aldo Manuzio el Canzoniere de Petrarca (1501) y la Divina Comedia de Dante (con el título de Terze Rime, 1502). Sus obras completas fueron publicadas en cuatro volúmenes en 1729.

\section{Las Prose della volgar lingua}

Las Prose di M. Pietro Bembo nelle quali si ragiona della volgar lingua, que es su título completo (1525), están escritas en forma de diálogo y divididas en tres libros. Constituyen uno de los pilares del Renacimiento italiano, porque es la obra fundacional de la lengua italiana tal como hoy la conocemos: la que establece por primera vez su uso, su gramática y su dignidad. Regula de modo certero y coherente el «volgare» (o lengua vernácula), fundándolo sobre los escritos de los grandes

${ }^{1}$ Hay una muy benemérita edición bilingüe de Los Asolanos, al cuidado de José María Reyes Cano (Barcelona: Bosch, 1990). Para el texto italiano, adopta la edición de Carlo DionisotTi -que mencionamos en la nota siguiente-, y para la traducción española recoge la única aparecida en España, en 1551, obra de un desconocido, tal vez el propio editor (Salamanca: Andrea de Portonaris). 
escritores toscanos del «Trecento» (siglo XIV), en particular Petrarca y Boccaccio. Por ello las Prose son el libro que culmina un tema debatido en el «Cinquecento»: la «Questione della lingua». Por otra parte, contribuyó a difundir, en Italia y en el exterior, el modelo poético petrarquista.

Aunque sus materiales se remontan a bastantes años antes, apareció sólo en 1525 en Venecia, publicado por Giovanni Tacuino $^{2}$. Esta obra está conectada con otras dos de Bembo muy anteriores, que acabamos de mencionar: su edición del Canzoniere de Petrarca (1501), y su edición de la Divina Comedia de Dante (titulada por él Terze Rime, 1502), ambas en la imprenta de Aldo Manuzio. Por vez primera, dos autores que escriben en «volgare» reciben la misma atención filológica que los clásicos latinos y griegos. La reflexión crítica sobre ambos autores, más Boccaccio, sustenta la teorización de las Prose, como veremos en breve.

\subsection{Los interlocutores}

El libro está dedicado al cardenal Giulio de’ Medici, que en 1524 sería elegido papa con el nombre de Clemente $\mathrm{VII}^{3}$. Escrito en forma de diálogo, se sitúa ficcionalmente en el año 1502, con cuatro interlocutores muy queridos para Pietro Bembo,

${ }^{2}$ Existe otra edición póstuma de las Prose (Firenze: Torrentino, 1549). Entre las ediciones modernas, se considera de referencia la de Carlo DionisotTi: Prose e Rime (Torino: UTET, 1960; $2^{\mathrm{a}}$ ed. aum., 1966; reediciones, 1989 y 1992). En español contamos con una primera traducción, excelente, en edición bilingüe, por Oriol Miró Martí (Bembo, Pietro: Prosas de la lengua vulgar. Madrid: Cátedra, 2011). De ella tomaremos las citas.

${ }^{3}$ El papa Clemente VII, Giulio de’ Medici (1478-1534), era hijo natural de Giuliano de’ Medici (1453-1479), y sobrino de Lorenzo de' Medici, el Magnífico (14491492), quien se ocupó de él tras el asesinato de su padre. En 1513 fue nombrado arzobispo de Florencia por su primo el Papa León X (Giovanni de’ Medici, 14751521), y posteriormente cardenal. Fue papa entre 1523 y 1534.

No hay que confundir al padre de Clemente VII, Giuliano de' Medici (hijo de Cosimo y hermano de Lorenzo), con su sobrino homónimo Giuliano de'Medici, Duque de Nemours (1479-1516), llamado también Giuliano II de’ Medici, hijo segundo de Lorenzo de’ Medici, junto a sus hermanos Piero y Giovanni. Este personaje, Giuliano, igualmente apodado Il Magnifico, como su padre Lorenzo, fue gran amigo de Pietro Bembo, y aparece como interlocutor en las Prose della volgar lingua. Por su matrimonio con Filiberta, hija del duque de Saboya, recibió el título de duque de Nemours. Gobernó en Florencia desde 1512 hasta su prematura muerte en 1516. 
retratados en ese momento de 1502: Carlo Bembo, que moriría en 1503, hermano muy amado de Pietro, y portavoz de sus tesis; Giuliano de’ Medici, «Il Magnifico», hijo de Lorenzo, amante de la poesía (aparece igualmente como interlocutor en otro de los grandes libros del momento: Il Cortigiano, de Castiglione; Giuliano moriría a los 37 años, en 1516); Ercole Strozza, célebre poeta en lengua latina, que había albergado a Pietro en su casa de Ferrara (y moriría en 1508); y Federigo Fregoso, noble genovés (que llegaría a ser cardenal y el más longevo, pues murió en 1541).

Por lo tanto, Pietro Bembo plasma la acción y el marco del diálogo en un pasado/presente ucrónico y feliz, con su amadísimo hermano y con sus grandes amigos, todos vivos y desbordantes de elegante cultura.

Según el modelo ciceroniano, los protagonistas del diálogo tienen una precisa distribución de papeles: Ercole defiende la superioridad del latín sobre el «volgare» o romance; Giuliano sostiene la dignidad del florentino contemporáneo, basado en los autores modernos y en el uso común de la lengua; Federigo, por su parte, defenderá la tradición del «volgare» trazando una especie de historia de la literatura, y mostrando un buen conocimiento de la poesía antigua, provenzal e italiana; y Carlo establecerá el criterio suprahistórico de los grandes modelos italianos: Petrarca y Boccaccio.

\subsection{Estructura de las Prose}

Se proponen las Prosas dar carta de naturaleza a la literatura en «volgare», y para ello tiene que establecer las reglas lingüísticas y los modelos literarios. Por boca de Carlo, declara el autor que la excelencia de una obra literaria tiene que ser determinada, no por su éxito entre la muchedumbre, sino por la aquiescencia de un puñado de hombres doctos, a quienes corresponde educar a la multitud. La primera preocupación de Bembo será salvar la lengua italiana de sus precariedades y contingencias «cortesanas» (es decir, de las variantes lingüísticas de las distintas cortes que reinaban en las ciudades-estado de la época); remontarse al «Trecento» (s. XIV), y proponer como canónica la lengua 
toscana de ese siglo, dado que cuajó en sus excelentes escritores toscanos (Petrarca, Boccaccio). De este modo queda la lengua ya preparada para el futuro.

El Libro Primero sitúa la acción en casa de Carlo Bembo. Se suscita la cuestión de qué lengua debe adoptarse para escribir: ¿el latín es preferible al «volgare»? ¿Cuál, entre las muchas variantes del «volgare» hay que emplear? Carlo y Giuliano, en ágil debate, hacen la defensa de la lengua vulgar frente a Ercole, que considera al latín superior.

Mediante un examen de la historia de la lengua vulgar, se concluye que la lengua italiana que hay que usar para la escritura -e incluso para el habla- es el toscano del «Trecento», puesto que su excelencia ha sido fijada en la lírica de Petrarca y en la prosa de Boccaccio. (Dejando de lado la poesía de Boccaccio, Bembo propone como modelo para la prosa no la de las «novelle», demasiado baja y coloquial, sino la del proemio del Decameron. Porque, en su opinión, es evidente la superioridad de la escritura y de su norma, sobre la lengua hablada y su cambiante uso. Una lengua existe cuando existe una literatura.

En este Libro Primero se aborda también la relación entre el italiano y el provenzal, tanto en la lengua como en la literatura. Federigo sostiene que la versificación toscana desciende de la provenzal (saltándose completamente la poesía siciliana, siglo XIII, «Duecento»):

La lengua florentina ha tomado las rimas de los poetas provenzales, más que de otros, y ha tenido a éstos por maestros [...]; y buena muestra de lo que digo puede ser [...] los muchos tipos de canciones que los florentinos, tomándolos de los provenzales, han llevado a Toscana.

Remontándose a los autores del «Trecento» (Dante, Petrarca, Boccaccio), nuestro autor borra la literatura contemporánea y también la lengua «cortesana» de su época. (De sus contemporáneos, sólo salva a Lorenzo de’ Medici, padre de Giuliano).

$$
* * *
$$

Interrumpiendo el estilo dialogado, el LiBro SEgundo se abre con una interpelación o apóstrofe de Pietro Bembo al cardenal 
de’ Medici, donde de manera sucinta, mediante enumeración de poetas y breves comentarios, traza una historia de la literatura italiana en prosa y verso, que culmina en sus autores favoritos. Y a continuación cede la palabra a sus personajes, para expresar los diálogos que tuvieron lugar el segundo día. El Libro Segundo se va a ocupar de elocutio: cuestiones estilísticas de poesía y de prosa. Aquí es donde expone su teoría métrica -que nosotros desarrollaremos en el epígrafe siguiente-. Elementos técnicos, de métrica y retórica del «volgare», y análisis de textos -sobre todo de Dante, Petrarca, y Boccaccio- ocupan el Libro.

En este segundo día se afronta otra cuestión espinosa, pero central en literatura: En qué reside la perfección formal, y cuáles son las reglas para emitir un juicio de valor adecuado. Vinculando la lengua literaria vulgar con la gran tradición clásica de la Retórica (Cicerón y Quintiliano sobre todo) y de la Poética (Horacio), establece un método donde el estilo, la selección léxica y la armonía de las formas son los criterios. Éstos se van deduciendo del análisis cuidadoso y admirativo del soneto que abre el Canzoniere de Petrarca ( «Voi, ch’ascoltate in rime sparse il suono»); pero también se desprende de críticas negativas a varios pasajes de Dante.

Concentra su análisis en la elección y disposición de las palabras («electio» y «dispositio verborum»). La elección debe adecuarse a la materia tratada, siguiendo la teoría de los tres estilos: palabras «graves, altas, sonoras, luminosas» para las materias graves; «leves, llanas, populares» para las materias bajas; y palabras "medias y templadas" para las materias medias. (Como en el De oratore de Cicerón, 29, 100). Por su parte, la disposición atiende a qué palabras van bien o mal juntas.

La elección de las palabras parece a Bembo el recurso central para una excelente elocución poética. Y la elección tiene dos «partes» fundamentales: dulzura («piacevolezza») y gravedad («gravità»):

[B]ajo la gravedad pongo la honestidad, la dignidad, la majestad, la magnificencia, la grandeza y otras semejantes; bajo la dulzura, comprendo la gracia, la suavidad, la hermosura, la afabilidad, las bromas, los juegos y cuantas haya de este tipo. (II, IX) 
Una composición puede ser agradable y no grave (como muchas de Cino da Pistoia); o bien grave y no agradable (como le sucede a menudo a Dante). Por el contrario, Petrarca cumple maravillosamente las dos condiciones.

Tanto la dulzura como la gravedad se expresan mediante tres elementos: dos de ellos, el sonido y el número, habían sido ya detectados y elaborados por la Retórica clásica (p. ej., Quintiliano, IX, 4); pero el tercero, la variación, es aporte propio de Bembo. Porque para evitar la rigidez en los esquemas y la monotonía hay que usar la moderación, y variar en la elección de las palabras. Ejemplificará todo esto en Petrarca, sumo poeta. Pero, antes de llegar a él, aportará un conjunto de «exempla» en negativo, a menudo procedentes de Dante.

$\mathrm{Al}$ sonido dedica el epígrafe $\mathrm{X}$, y lo define así:

El sonido es ese [concento] ${ }^{4}$ y esa armonía que en la prosa se genera de la composición de las palabras, y en el verso además de la composición también de las rimas. Ahora bien, como el [concento], que nace de la composición de muchas palabras, tiene origen en las palabras, y las palabras reciben calidad y forma de las letras que tienen, es necesario saber qué sonido dan cada una de estas letras, o separadas o acompañadas.

Examina el sonido de todas las letras, comenzando por las vocales, y hace observaciones curiosas. Por ejemplo, que la A es el mejor sonido «porque expresa una fuerza mayor, pues con los labios más abiertos lo emite y manda esa energía de forma más directa al cielo». De la I afirma: «Débil y ligero y desmayado y, sin embargo, dulce espíritu [...] es el de la I; porque su sonido no es tan bueno como el de las que se han dicho [A, E, O], aunque bastante suave». O bien, entre las consonantes: «tierna y delicada y agradabilísima es la L, y dulcísima entre sus compañeras. Al contrario, la $\mathrm{R}$ es áspera, pero de ánimo generoso».

Además del sonido y su armonía en el interior de las palabras, Bembo aborda a continuación la armonía de sonidos en las

\footnotetext{
${ }^{4}$ Traducimos nosotros la palabra italiana concento por la española homónima «concento», en vez de «concierto», como prefiere Oriol MiRó (p. 309). La palabra española concento (del latín concentus, ‘armonía') está ampliamente atestiguada tanto en los textos poéticos como en la teoría literaria de los Siglos de Oro. Significa 'canto acordado y armonioso de varias voces'.
} 
rimas. Nosotros aplazaremos esta teorización para tratar brevemente del siguiente Libro.

El Tercer Libro es el más voluminoso de las Prosas: ocupa tanto como las otras dos partes juntas. Y con razón, porque es una gramática completa del italiano, con sus componentes morfológicos: nombre, adjetivo, participio, artículo, pronombre, verbo, adverbio, preposición y conjunción. Estas categorías son examinadas con toda amplitud, profundidad y casuística. Sus fuentes, además de Cicerón y Quintiliano, son la Rhetorica ad Herennium, De compositione verborum de Dionisio de Halicarnaso, Rhetoricum libri de Jorge de Trebisonda, De vulgari eloquentia y Convivio de Dante. Entre los modernos, la Grammatichetta de Leon Battista Alberti y el Comento de Lorenzo de' Medici. Así, lo más importante del saber antiguo y del moderno se condensa en estas páginas. El libro tendrá tanta aceptación, que las Prosas, junto a la obra de Lionardo Salviati (Orazione in lode della fiorentina lingua, 1564), configurarán el purismo de la Accademia della Crusca (Florencia, 1583).

El tratamiento del tema, sin embargo, no es sistemático, lo que dificulta su lectura, así como la superabundancia de ejemplos. También la dificulta el que Bembo evite la terminología gramatical precisa y consolidada en el latín, recurriendo a perífrasis aproximativas, incluso para las definiciones más elementales. Así el «singular» y el «plural» son «el número del menos» y «el número del más»; el «presente» es el «tiempo que corre mientras uno habla»; etc.

\subsection{La teoría métrica}

Se incluye dentro del examen de la lengua literaria. Su exposición ocupa los epígrafes X-XXI del Libro Segundo. Tiene, pues, un desarrollo poco extenso.

Como señalamos antes, dentro de su estudio del sonido Bembo había distinguido entre la armonía de sonidos en el interior de las palabras, y la armonía de sonidos en las rimas. Y a las rimas dedicará tres epígrafes del Libro Segundo: XI, XII y XIII. 


\subsubsection{Tipos de rima: reguladas, libres y mixtas}

El verso recibe elegancia del sonido de las letras que lo configuran -afirma Federigo-, pero también recibe armonía y belleza de las rimas (II, XI). Además, la rima va a servir como criterio clasificatorio para los poemas. Señala que normalmente las rimas son de tres tipos: reguladas, libres y mixtas.

Son REGULADAs las que se despliegan en Tercetos,

llamados así porque toda rima se pone tres veces, o porque siempre comenzando la nueva rima con ese mismo orden de tres en tres se completa y cierra la empezada. Y por eso, estos tercetos así juntos se tienen todos como una sola cosa, como anillas pendientes unas de otras, de tal forma que algunos llaman a este tipo de rima Cadena; se cree que Dante fue quien la inventó, pues con ella escribió su poema, y antes de él no se sabe de nadie que la usara.

También es regulada la que llamamos Octava rima, porque sus composiciones se encierran en ocho versos. Se cree que fueron los poetas sicilianos quienes la crearon, usando sólo dos tipos de rimas [ABABABAB]. A ellas los poetas toscanos añadieron una tercera rima al final, en los dos últimos versos [ABABABCC].

Son igualmente reguladas las Sextinas, ingenioso hallazgo de los poetas provenzales. Su inventor (había dicho en I, IX) se sabe que fue Arnaut Daniel, «que hizo una sin igual». «O como aquellas otras canciones, que tienen todas sus rimas hechas con las mismas palabras», cuyo uso comenzó el provenzal Peire Rogiers. Como en Dante: «Amor, tu vedi ben que questa donna» ${ }^{5}$.

\footnotetext{
${ }^{5}$ Obsérvese cómo Bembo no parece incluir este segundo tipo de canción dentro de las «sextinas». En los estudios literarios italianos, este segundo tipo suele ser llamado «sestina doppia», y es rarísimo. Sorprende que Bembo lo mencione, siendo tan escaso, y él tan amante de las generalidades. Por otra parte, decir que «todas sus rimas» están "hechas con las mismas palabras» es una formulación inexacta y ambigua (¿todas las rimas del poema? ¿todas las rimas de la estrofa?). Éste es su esquema:
}

ABAACAADDAEE
EAEEBEECCEDD
DEDDADDBBDCC
CDCCECCAACBB
BCBBDBBEEBAA
(Contera) AEDDCB 
Por el contrario, son LIBREs «las que carecen de toda ley en el número de versos o en la manera de rimarlos, pues cada uno forma su rima como más le gusta; y éstas son llamadas por todos Madrigales», bien porque cantasen al principio cosas materiales y groseras, en esa manera de rimas sueltas e igualmente materiales; o bien porque trataran preferentemente de amores pastoriles y esas gentes contaran hechos silvestres (como los latinos y los griegos en sus Églogas), tomando el nombre sus canciones de los rebaños («mandre», «mandriale») ${ }^{6}$.

Por último, son MIXTAS «aquellas rimas que tienen en parte normas y en parte son libres», como son los Sonetos y las Canciones. Los Sonetos tienen prefijado el número de versos, y en parte las rimas. Pero para el orden de las rimas y su número «no existe más regla que el deleite». Los antiguos hicieron sonetos de dos rimas, e incluso introducían rima interna7.

La llamada "sestina doppia» de Dante tiene 12 versos en cada una de las 5 estrofas (no 6 versos y 6 estrofas, como en la sextina de Arnaut Daniel). Además de este rasgo, se caracteriza por la repetición insistente de 5 palabras (no de 6), reiterándose mucho y con un orden prefijado cada una de ellas en cada una de las estrofas. No debe confundirse con la «sestina doppia» de Petrarca, que son 2 sextinas normales consecutivas; ésta sí ha tenido amplia descendencia, también en España, mientras la de Dante es prácticamente un «unicum». Veamos sus dos primeras estrofas, para que se aprecie la persistencia de sus rimas y su distinta distribución respecto a la sextina normal:

"Amor, tu vedi ben che questa donna / la tua vertù non cura in alcun tempo,/che suol de l'altre belle farsi donna; / e poi s'accorse ch'ell'era mia donna / per lo tuo raggio ch'al volto mi luce,/ d'ogni crudelità si fece donna; / sì che non par ch'ell'abbia cor di donna,/ ma di qual fiera l'ha d'amor più freddo:/ ché per lo tempo caldo e per lo freddo / mi fa sembiante pur come una donna / che fosse fatta d'una bella petra / per man di quei che me' intagliasse in petra. //

Ed io, che son costante più che petra / in ubidirti per bieltà di donna, / porto nascoso il colpo de la petra, / con la qual tu mi desti come a petra, / che t'avesse innoiato lungo tempo, / tal che m'andò al core ov'io son petra. / E mai non si scoperse alcuna petra /o da splendor di sole o da sua luce, / che tanta avesse né vertù né luce / che mi potesse atar da questa petra, / sì ch'ella non mi meni col suo freddo / colà dov'io sarò di morte freddo».

${ }^{6}$ En la conexión etimológica entre «madrigale» y «mandrialis» está siguiendo Bembo a Antonio da Tempo; pero no así en la conexión con «materialis», que no aparece en el jurista paduano. (DA Tempo, Antonio: Summa Artis Rithimici Vulgaris Dictaminis [1332]. Bologna: Commisione per i Testi di Lingua, 1977).

${ }^{7}$ Bembo, usando la figura retórica de la "praeteritio», dice que omitirá hablar de que Dante llama soneto a una canción de la Vita Nuova. En realidad son dos poemas con esa misma estructura: «O voi, che per la via d'Amor passate» (cap. VII) y «Morte villana, di pietà nemica» (cap. VIII). Pero sucede que Dante lleva razón, y no Bembo, pues son sonetos «rinterzati» o «dobles», definidos por Tempo. 
A su vez, en las Canciones «se puede tomar cualquier número, tipo y rima de versos para componer la primera estrofa». Pero «una vez escogidos, será necesario seguirlos en las otras [estrofas] con las mismas leyes que el poeta ha tomado libremente».

Lo mismo sucede con ese tipo particular de canción que se llama Balada. Cuando la balada tiene más de una estrofa, se llama «vestida»; y cuando solamente tiene una, «desvestida». (Esta clasificación sólo la hemos visto mencionada en Bembo).

Nuestro autor no quiere que el lector piense que, al clasificar las rimas y mencionar algunos tipos poemáticos, ha agotado ya con ello el repertorio de los poemas, que en realidad son numerosísimos. Por eso cautamente afirma: «todas aquellas rimas que estos [tres] tipos encierran, [...] pueden sin duda ser muchas».

\section{3. 2. Lejanía o proximidad de las rimas: gravedad y dulzura}

A continuación, en los epígrafes XII y XIII, va a entrar en consideraciones estilísticas acerca de la proximidad o la lejanía de las rimas dentro de la estrofa o poema: Suenan con mayor gravedad las rimas que están más alejadas entre sí, y más dulcemente las que están más cerca:

Lejanas llamo a las rimas que se responden de lejos y que tienen otras rimas interpuestas y otros versos entre sí; más cercanas asimismo cuando no tienen entre sí ninguno, sino que dos versos terminan con una misma rima; cercanísimas luego esas otras que terminan en dos versos rotos; e incluso muchísimo más cercanas que éstas y aquéllas, [cuando] terminan en muchos versos enteros y muchos rotos, sin intromisión de ninguna otra rima.

El soneto «rinterzato», invención de Guittone d’Arezzo (s. XIII), intercala heptasílabos entre los endecasílabos, con este esquema: $\mathrm{A} a \mathrm{BA} a \mathrm{~B}, \mathrm{~A} a \mathrm{BA} a \mathrm{~B}, \mathrm{C} c \mathrm{D} d \mathrm{C}$, $\mathrm{D} d \mathrm{C} c \mathrm{D}$. La confusión de Bembo se debe a que este tipo de sonetos ya no se usaba en su época; y también a que Bembo no se interesa más que por los esquemas usados por Petrarca, entre los que no se encuentra éste.

Bausi y Martelli también comentan este «singular error métrico cometido por Bembo», y señalan «cómo, probablemente, no conocía la Summa de Antonio Da Tempo (por lo demás, publicada poco antes, en el 1509, en Venecia)». (Cfr. BAusi, Francesco, y MARTELLI, Mario: La metrica italiana. Teoria e storia. Firenze: Casa Editrice Le Lettere, 1993, p. 175. Traducimos nosotros). 
No contentos con esto, los antiguos incluso las colocaban en mitad del verso, y a veces más de una por verso. Por el contrario, la sextina sería el mejor ejemplo de «maravillosa gravedad», con tanta demora y tanto orden en sus rimas. Se compensa el sonido gravísimo de las rimas en la sextina, con la dulzura que se genera al repetirse la rima en final de estrofa y comienzo de la siguiente. Además, como las rimas son de palabra, una proximidad mayor entre las restantes rimas de la sextina, produciría fastidio.

Hay un peligro en el alejar mucho las rimas: se puede perder totalmente la armonía. El poeta debe guiarse por su oído, pero en general «no está bien interponer más de tres o cuatro o incluso cinco versos entre las rimas; y éstos, aún muy raramente». Petrarca sobrepasó este límite en la canción «Verdi panni», donde interpuso hasta siete versos entre las rimas, quizá imitando a los trovadores; aunque en las demás canciones se atuvo a la regla.

A su vez, la proximidad o vecindad de las rimas genera placer y dulzura; y tanto más cuanto la proximidad sea mayor. Por eso las canciones, que tienen muchos versos rotos, resultan graciosas y suaves. Algunas canciones de Petrarca tienen muchos versos rotos, como «Chiare, fresche e dolci acque», llena de dulzura y gentileza. Pero no conviene poner más de dos versos con una misma rima, porque si no, «el placer se envilece».

Por otra parte. los versos que tienen rima en el medio son duros y ásperos. Porque, imponiéndose el poeta tan dura regla, no puede elegir las palabras o disponerlas a su manera, sino que tiene que acomodarse al imperio de la rima. Y tanta repetición de rimas genera estrépito, más que sonido. Como en la canción de Guido Cavalcanti «Donna mi prega, perch’io voglio dire». Guido y los toscanos tomaron este modo de los provenzales, que lo usaron a menudo. Petrarca lo rehuyó, y nunca puso dos rimas vecinas o cercanas en el medio de ningún verso suyo; excepto en la canción «Mai non vo’ più cantar, com’io soleva» ${ }^{8}$. Esta canción, quien por ello la considerara algo dura, no erraría demasiado. Además, está trufada de numerosos proverbios, como era la moda entonces, y eso también genera cierta aspereza y dureza. Por el contrario, las canciones de Petrarca que tienen todos sus

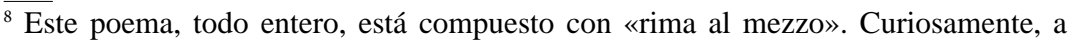
pesar de las críticas de Bembo a esta canción, él mismo la imita en su «Rima LV». 
versos enteros, producen gravedad, como «Nel dolce tempo de la prima etade».

Baste esto en cuanto al sonido.

\subsection{3. «Número» y «tempo» en las sílabas. Sílabas largas y breves. Acentos. Movilidad acentual}

El número ['ritmo'; lat. numerus] es el tempo que se da a las sílabas, o largo o breve; bien por obra de las letras que integran la sílaba, bien por razón de los acentos que se da a las palabras, o bien por ambos.

No quiere repetir Federigo lo que dicen los griegos [sobre la cantidad], pues se aplica más a su lengua que a la nuestra. En nuestro vulgar siempre es larga la sílaba encima de la cual está el acento; y breves las demás. «Su colocación más en un sitio que en otro, mucha gravedad o dulzura pone y quita en prosa y en verso».

Este asiento o colocación («giacitura») del acento puede tener lugar: o en la última sílaba, o en la penúltima, o en la antepenúltima, «porque más de tres sílabas no suelen estar bajo un mismo acento». Analiza con sutileza el «peso» de las sílabas en las palabras agudas, llanas y esdrújulas, y examina su repercusión en los versos: En las rimas esdrújulas hay que contar una sílaba menos, porque el verso es ligero. Por el contrario, la sílaba de los versos agudos pesa mucho y vale por dos; de ahí que haya que contar una sílaba más; aunque pesan más o menos según las letras que la integren. Y las palabras llanas, por su parte, son equilibradas. A veces dan gravedad a las palabras «cuando están repletas de vocales y de consonantes capaces de ello; y a veces dulzura, cuando se encuentran desnudas y muy pobres de consonantes y de vocales, o están de aquellas que sirven para la dulzura cubiertas bastante y vestidas».

Examina luego textualmente estos principios en el epígrafe siguiente, el XV, y lo hace sobre el proemio del Decameron de Boccaccio. Así muestra la gravedad de las palabras llanas: «Umana cosa è l'avere compassione agli afflitti». Y la compara con los efectos de otros tipos de palabra, esdrújulas o agudas. Similarmente procede con un verso de Petrarca («Voi ch’ascoltate 
in rime sparse il suono»), cuyo orden de palabras altera, estropeando el ritmo. Porque no se puede quitar ningún acento de su lugar, y es necesario que haya un acento en la $4^{\mathrm{a}}$ sílaba, o en la 6 , además de en $10^{\mathrm{a}}$ posición.

Pregunta Ercole Strozza a Federigo en el siguiente epígrafe por las palabras sobresdrújulas («germinano», «terminano», etc.): si pueden estar bajo el gobierno de un solo acento. Federigo responde que sí, aunque esto sucede raramente. Un acento puede recoger hasta cinco sílabas; como p. ej. en Boccaccio «portàndosenela».

El acento no puede recaer en sílaba breve, como entre griegos y latinos, porque en italiano el acento la convierte en larga. Por otra parte, en poesía el acento puede desplazarse en la palabra. Como leemos en los antiguos poetas, "pièta» en vez de «pietà».

Continúa ocupándose Bembo del «tempo» (lento en las sílabas largas; rápido en las breves) en el epígrafe XVII. Las sílabas poseen tanta mayor gravedad cuanto más largo tempo tienen en sí mismas: cuantas más consonantes y vocales entran en cada sílaba. Por ejemplo: «Compassione agli afflitti», de Boccaccio. O en Petrarca, es gravísimo el verso: «Fior’, frond', erb’, ombr', antr', ond', aure soavi». Y también es más llena la palabra «suoi» que «poi»; «miei» que «lei»; etc. Y así como la densidad de las letras da a las voces o palabras gravedad, inversamente, su escasez les da dulzura.

Esto completa y cierra la exposición sobre la fuerza y el valor del número ('ritmo').

\subsubsection{La variación}

Es la tercera causa del escribir bien, junto al sonido y al número. En el epígrafe XVIII se ocupa Bembo de la variación, que sirve para ahuyentar la saciedad. Por ejemplo: entre voces o palabras graves, poniendo alguna ligera o baja; entre muchas palabras con acento en penúltima sílaba, intercalando alguna aguda; introduciendo, entre palabras regias, algunas populares; etc.

Tampoco conviene abusar de una misma figura retórica, ni de una determinada parte de la oración. Así Boccaccio varió en los comienzos de cada una de las cien «novelle». Y Petrarca varió usando versos enteros y rotos, rimas próximas y alejadas. 


\subsubsection{Decoro y persuasión. Disposición y composición}

Trata de estas «parti» o cualidades del buen escribir en el epígrafe XIX. Y en el XXI expodrá ejemplos de decoro, disposición y composición.

En cada escritor, hay que ver cuánta dulzura y cuánta gravedad ha esparcido por sus obras. Pero además, para juzgar a un escritor hay que tener en cuenta los otros tres factores o «parti»: el sonido, el número y la variación. Y además, el decoro y la persuasión.

¿Observa el escritor el decoro de los estilos, la conveniencia o adecuación? Creyendo usar voces graciosas, el escritor puede caer en el ridículo, o bien creer dulces las voces insípidas. Buscando la gravedad fácil, se puede caer en la austeridad del estilo. $\mathrm{O}$ creer hermosas las palabras afectadas.

Igualmente importante es la persuasión, sin la cual no puede haber ni gravedad ni dulzura. La persuasión da fuerza y virtud al discurso. La persuasión conmueve al lector y le hace asentir ante lo que lee. El campo de la prosa es mucho más amplio, espacioso y libre que el del verso. El arte oratoria enseña la persuasión más detalladamente.

Pasando al campo de la crítica literaria concreta, el grupo de amigos se enzarza en disquisiciones lingüísticas sobre palabras de los autores. P. ej., critican en Dante el uso de «so», florentinismo, en vez de «suo»; o el uso de «signorso», vulgarismo. Estas palabras aparecen también en Boccaccio, pero en contextos más apropiados.

En definitiva, Boccaccio y Petrarca son los más excelsos escritores, aunque Boccaccio muchas veces no ha sido prudente, ya que le fallaba el juicio al escribir; no obstante, escribió con hermoso estilo:

Y digo de ellos dos todavía más, que bonísimos escritores son por encima de todos los demás, y también que la manera de escribir de los toscanos hoy en día no es tan buena como aquélla en la que escribieron ellos; y así será hasta que venga otro escritor que haya diseminado y esparcido más que ellos en sus composiciones las cosas de las que hemos hablado. 
Estas palabras de Bembo resultan muy reveladoras de su posición estética: el punto culminante en la historia de la Literatura italiana (y por lo tanto también de su lengua) es -como decíamos antes- el «Trecento», con Petrarca y Boccaccio a la cabeza, y poetas como Dante, Cino da Pistoia, Guittone d'Arezzo y otros, a continuación. En los tiempos presentes («Quattrocento» y «Cinquecento») nadie los iguala. No obstante, en el futuro pueden llegar otros genios que renueven la lengua y la literatura italianas.

\subsection{6. ¿Quién es mejor poeta: Dante o Petrarca?}

Tras la docta exposición anterior, se calla Messer Federigo. En este momento el Magnífico, Giuliano de’ Medici, plantea a Messer Ercole esta espinosa pregunta, sobre la cual existen encendidas discrepancias. Aunque los que prefieren a Petrarca son infinitos, a otros muchos satisface más Dante por la grandeza y variedad del tema. Ahora bien, ¿el tema es el criterio máximo de calidad? No: el tema es lo que da al poema su estilo elevado, humilde o mediano; pero por sí mismo no es ninguna prueba de calidad. Por ejemplo: el siciliano Teócrito cantó materia humilde con gran altura poética, y ha sido considerado mejor poeta entre los griegos que Lucano entre los latinos, a pesar de que Lucano cantó un tema regio y altísimo. Pero también es cierto que unos temas gustan más que otros.

Messer Ercole responde, relatando la anécdota de cuando Pietro Bembo y otro amigo se alojaron en su casa de Ferrara. El amigo sostenía que el mejor poeta era Dante, por haber tratado de tantos temas divinos, humanos e infernales. Ahora interviene Carlo Bembo; afirma que ése es el gran argumento de los dantistas, y lanza varias descalificaciones a Dante:

$1^{\text {a }) ~ F a l t a ~ d e ~ « d e c o r o » ~ e n ~ e l ~ n i v e l ~ d e l ~ e s t i l o . ~ D e b i o ́ ~ D a n t e ~ l i m i-~}$ tarse en su Comedia al nivel textual medio, «mediocris», propio de la «comedia»:

Aunque, a decir verdad, cuánto más loable hubiera sido que él de menos alta y de menos amplia materia hubiera escrito, y hubiera mantenido aquélla siempre en su estado mediocre, cosa que no hizo, en lugar de que [...] se dejara caer a menudo en las cosas más bajas y más viles. 
$2^{a}$ ) Falta de «decoro» por soberbia, por «hybris»:

Y cuánto sería incluso mejor poeta de lo que es, si en sus rimas no hubiera querido aparecer ante los hombres como algo más que como un poeta. Cuanto de cada una de las siete artes y de la filosofía, y además de todas las cosas cristianas, ha querido parecer maestro en su poema, menos sumo y menos perfecto ha sido en su poesía.

$3^{\text {a }) ~ F a l t a ~ d e ~ « d e c o r o » ~ p o r ~ l e x i s ~ d e s m e d i d a: ~}$

Porque con la voluntad de poder escribir sobre cualquier cosa que le viniera en mente, aunque fuera poco apropiada o completamente inadecuada para el verso, usando muy a menudo palabras latinas, o extranjeras que no han sido recibidas en la Toscana, o palabras viejas y abandonadas del todo, o caídas en desuso y ásperas, o inmundas y feas, o durísimas, y al contrario, alguna vez cambiando y corrompiendo las puras y nobles $\mathrm{y}$, a veces, sin criterio alguno o regla formándolas y fingiéndolas a partir de ellas.

$4^{a}$ ) Juicio conclusivo mediante doble comparación:

Ha obrado de tal modo que su Comedia puede justamente asemejarse a un bello y espacioso campo de trigo lleno de avena y de paja y de hierbas estériles y dañinas, o a una vid no podada a tiempo y que luego en verano está tan llena de hojas y de pámpanos y de zarzas, que terminan por corromperse las bellas uvas.

¡Terrible e injusto ataque! Una feroz inquina contra Dante parece mover a Bembo aquí -como sucede también en el resto de las Prose-. Podemos pensar que, tras esta agresividad, se encuentra una radical discrepancia estética: Dante es un poeta grandioso, sublime, muy alejado de la elegancia suave, culta y sin sobresaltos («mediocritas», estilo medio) que Bembo amaba. Pero también, quizá, podríamos sospechar una razón edípica tras esa animadversión. (Recordemos que el padre de Bembo, en su admiración intensa por Dante, hizo erigirle monumentos en varias ciudades italianas). 
El epígrafe siguiente, el XXII, cierra la teoría métrico-estilística. Strozza se muestra de acuerdo con sus tres amigos acerca de la superioridad de Petrarca sobre Dante; afirma que hoy ha oído muchas cosas aleccionadoras de Messer Carlo y Messer Federigo; e invita al Magnífico a volver a platicar al día siguiente en casa de Bembo, con los otros interlocutores. El Libro III ya visto, el de la Gramática italiana, será el fruto de ese nuevo encuentro.

\section{Conclusión: importancia histórico-lingüística de las Prose. Escasa relevancia de su teoría métrica}

Este libro fue -como hemos señalado antes- una novedad absoluta, que influyó tanto en la lengua como en la literatura italianas. Desde la elección del diálogo ciceroniano como método expositivo -novedad en el «volgare», que sería muy seguida-, hasta la resolución de las dudas gramaticales que planteaba el uso del aún joven «volgare». Por eso Bembo funda el Clasicismo del «Cinquecento», conexionando Gramática, Teoría y Crítica literaria. De su importancia gramatical ya hemos tratado. Y para la Literatura, este libro puede ser considerado un primer intento de Historia literaria italiana e incluso de Crítica.

En cambio, su teoría métrica nos parece escueta y de poca enjundia. Lo más interesante creemos que es la clasificación de los tipos poemáticos («rimas») en regulados, libres y mixtos. Porque a Bembo lo que le interesa es el andamiaje métrico (los mencionados tipos de rimas), y no descender a la realidad métrica de los poemas. Dentro de esas grandes líneas que intenta establecer, se inserta su deseo de trasladar los conceptos latinos cuantitativos de «numerus» y «tempus», ligándolos entre sí y apoyándolos -con redacción bastante confusa- en el moderno acento. Dicho con palabras más claras: el ritmo de los versos (lat. numerus) depende de los acentos del verso, y de la velocidad o tempo que los acentos imprimen al verso: más rápido en las sílabas átonas y con pocas letras, y más lento en las tónicas y con muchas letras.

Además, es destacable un conjunto de finas observaciones estilísticas: sobre la gravedad y la dulzura de las rimas en 
función de su lejanía o proximidad entre sí; sobre el «peso» de las sílabas en las rimas agudas, llanas y esdrújulas; sobre la necesidad de variación textual; etc.

Su deseo normativo, su constante fijación de criterios -también literarios-, le lleva a sentar cátedra en el dificilísimo tema de la valoración. Los interlocutores de las Prose coinciden en que los criterios para juzgar a un escritor son cinco: El sonido, el número, la variación, el decoro y la persuasión.

$* * *$

Una somera comparación con la Poetica de Trissino, casi coetánea (1529), cuya síntesis expusimos en las páginas de esta misma revista, Rhythmica ${ }^{9}$, permite ver la cantidad de elementos métricos omitidos en el sistema bembiano:

1. ${ }^{\circ}$ : No establece una panorámica de los tipos poemáticos italianos. No le interesa entrar en ese difícil y minucioso campo.

2. ${ }^{\circ}$ : La veneración de Bembo por el «Trecento» y su desdén por la literatura contemporánea, hacen que no vea ni describa la mayor novedad métrica del «Cinquecento» (mérito principal de Trissino): el verso suelto («sciolto»). Igualmente, ignora los demás experimentos «bárbaros» de su época: los intentos por trasladar el hexámetro y otros ritmos grecolatinos a la lengua italiana.

3. ${ }^{\circ}$ : Por otra parte, dentro de su reducido campo de observación -básicamente Petrarca-, no presta atención a la realidad de sus poemas: metros, distribución de acentos, estrofas o no estrofas, esquemas de rimas, etc. No trata -salvo en una brevísima mención- el ritmo acentual de los versos en concreto. Llamativo es su escasa atención a la estrofa («stanza») -salvo en el caso obligado de los «tercetos» o la «octava rima», o en la "canción» [petrarquista o de estancias]. En cambio, resulta muy curiosa su

${ }^{9}$ PARAíso, Isabel: «Giangiorgio Trissino: innovador poeta y máximo teórico de la métrica italiana renacentista». Rhythmica, Revista Española de Métrica Comparada, 2011, año VIII, no ${ }^{\circ}$, pp. 111-142. 
distinción entre baladas «desvestidas» (con una sola estancia) y «vestidas» (con varias).

En el nivel general de la teoría métrica, incluso, no aparece clara la distinción entre rima y poema. (Esto se encuentra favorecido por el llamar en la época «rime» a los poemas aislados; p. ej. las Rime de Petrarca, o las propias de Bembo, Rime,1530. Trissino disuelve nítidamente la ambigüedad llamando a las rimas «desinenze»).

$$
* * *
$$

La teoría métrica de Bembo ha recibido muy diversas valoraciones. Desde quienes ni siquiera hablan de ella, como Oriol Martí, el muy benemérito traductor de las Prosas; hasta quienes aseguran que es el análisis más influyente del Humanismo, y que está vigente hasta hoy. Como Richard Andrews, el editor moderno de Tempo:

Quien no muestra en absoluto haber leído la Summa es Bembo, a juzgar por sus capítulos de versificación en el segundo libro de las Prose. Así Antonio no contribuyó [...] al más influyente y más representativo análisis humanístico del verso italiano. De hecho, las formulaciones métricas de las Prose della Volgar Lingua, fundadas en otras fuentes o en ninguna fuente, dieron un impulso nuevo y hasta hoy definitivo a tales análisis ${ }^{10}$.

Y en el medio, diversas matizaciones. Es frecuente referirse a Bembo como el que «codifica nella teoria l'uso petrarchesco», como hace Pietro Beltrami ${ }^{11}$. Ciertamente, la teoría métrica de Bembo tiene como horizonte exclusivo Petrarca y su Canzoniere. Francesco Bausi y Mario Martelli ${ }^{12}$ resumen magníficamente -a nuestro entender- la posición teórico-poética de Bembo:

Las Prose de Bembo [...] conceden poco espacio a la métrica. Bembo [...] se limita de hecho a afirmar que las rimas fueron «graziosissimo

${ }^{10}$ Traducción y cursivas nuestras. La cita, en: Summa Artis Rithimici Vulgaris Dictaminis, cit., p. VIII.

${ }^{11}$ Beltrami, Pietro: La metrica italiana. Bologna: il Mulino, 1991, p. 98.

${ }^{12}$ Bausi, Francesco, y Martelli, Mario: La metrica italiana, cit., pp. 174-175. Traducción y cursivas nuestras. 
ritrovamento» [felicísimo hallazgo], puesto que dan a los metros italianos esa armonía y belleza que le daba a los latinos la variada sucesión de los pies. [...] [A]firma además que las formas italianas se dividen en tres categorías: formas reguladas [...], formas libres [...] y formas mezcladas [...]. La actitud de Bembo [...] se coloca en las antípodas de la posición de Trissino, cuya Poética, de estricta observancia aristotélica, es ciertamente la obra más aguerrida y completa del siglo en el plano de la teoría y del análisis métrico (precisamente Trissino, no por casualidad, sacó a la luz e hizo conocer el De vulgari eloquentia dantesco ${ }^{13}$ ).

Hay que subrayar, emblemáticamente, la diversa atención a los hechos formales, y la diversa competencia métrica de los dos literatos [Bembo y Trissino] (representantes de dos opuestas direcciones culturales y de poética).

Estamos de acuerdo con el cualificado juicio de Bausi y Martelli. Por nuestra parte, sólo añadimos, como juicio global, que las Prosas son ciertamente el monumento fundacional de la Gramática italiana, y quizá también de su Historia y Crítica literarias; pero en lo que atañe a la Métrica no pasa de ser un documento curioso, más notable por la personalidad que lo produjo que por sus méritos intrínsecos.

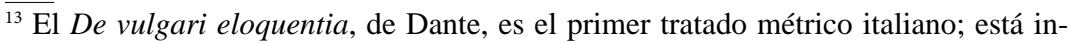
completo. El segundo es el citado de Antonio da Tempo. 